\title{
Predictors of low back pain among secondary school teachers in Malaysia: a longitudinal study
}

\author{
Eva Nabiha ZAMRI ${ }^{1,3}$, Victor Chee Wai $\mathrm{HOE}^{1,2}$ and Foong Ming MOY ${ }^{1 *}$ \\ ${ }^{1}$ Centre for Epidemiology and Evidence-Based Practice, Department of Social \& Preventive Medicine, \\ Faculty of Medicine, University of Malaya, Malaysia \\ ${ }^{2}$ Centre for Occupational and Environmental Health-UM, Department of Social \& Preventive Medicine, \\ Faculty of Medicine, University of Malaya, Malaysia \\ ${ }^{3}$ Cluster of Lifestyle Science, Advanced of Medical \& Dental Institute, Malaysia
}

Received June 20, 2019 and accepted October 21, 2019

Published online in J-STAGE October 31, 2019

\begin{abstract}
Low back pain (LBP) is prevalent among workers both in developed and developing countries. School teachers represent a high proportion of the working population in Malaysia. However, there is a lack of longitudinal study on predictors and course of LBP among teachers. Therefore, this study aimed to determine the predictors and course of LBP among secondary school teachers. Longitudinal data of 701 teachers in Selangor, Malaysia were collected from May 2015 to October 2016. Associations between predictors and LBP were analysed using logistic regression and reported as odds ratio (OR) and $95 \%$ confidence interval (CI). At 12-month of follow-up, $44 \%$ (95\%CI: $40.6 \%, 48.0 \%)$ of the participants reported having LBP. In the regression model that included all risk factors, only LBP at baseline (OR 10.43, 95\%CI: 6.19, 17.58) was associated with LBP at 12-month follow-up. When LBP at baseline was removed from the model, anxiety symptom (OR 2.51, 95\%CI: 1.19, 5.30) and lifting heavy weights (OR 4.16, 95\%CI: $1.40,12.30)$ were found to be significantly associated with LBP at 12-month follow-up. In conclusion, issues on anxiety and lifting heavy weights should be addressed to reduce the occurrence of LBP despite the presence of health condition itself (LBP at baseline).
\end{abstract}

Key words: Low back pain, Anxiety, Teachers, Longitudinal, Malaysia

\section{Introduction}

The changes in education and school systems have contributed to the change in teachers' evaluation systems ${ }^{1 \text { ) }}$. Now, teachers need to spend more time entering students' progress using computers. These changes have led to more pressures on teachers, predispose them to both stress and ergonomic risk that may affect their physical health, which

*To whom correspondence should be addressed. E-mail: moyfm@ummc.edu.my

(C)2020 National Institute of Occupational Safety and Health includes musculoskeletal disorder (MSD). MSD is common problem among the working population including teachers. In general, school teachers demonstrated a high prevalence of MSD ranging from $39 \%$ to $95 \%{ }^{2-4)}$. Low back pain (LBP) is one of the more prevalently reported MSD among school teachers.

LBP is not a disease, but a constellation of symptoms which are usually acute and self-limiting ${ }^{5}$. It affects the performance at work and general well-being besides incurring a high economic burden on individuals, families, communities, industries, and government. Despite the social impact of LBP, little is known about the course of LBP due to the lack of longitudinal studies, particularly among 
school teachers. In a previous cohort study conducted on nurses with LBP, more than $50 \%$ of them reported LBP after 12 months $^{6}$. Another study on the general population also found that history of LBP was highly predictive for future LBP episodes ${ }^{7}$. Acknowledging the natural course of LBP, there is a need to conduct a longitudinal study to assess its course over time among school teachers.

The aetiologies of LBP are multifactorial, and there is growing evidence that highlights the importance of psychological factors in the experience of $\mathrm{LBP}^{8,9)}$. The contribution of psychological factors on LBP is best explained using the cognitive-behavioural model, such as the fear-avoidance model ${ }^{10)}$. Examples of psychological factors described in this model include pain catastrophising, fear-avoidance belief, and emotional distress. Briefly, this model attempts to explain that pain experience is interpreted catastrophically, leading to pain-related fear and behavioural avoidance. The avoidance behaviour leads to reduce physical activity level and fosters negative psychological consequences including low mood. This cycle might account for the poor prognosis of LBP. Evidence from a recent Cochrane systematic review illustrated the effectiveness of cognitive-behavioural treatment in short term pain relief among those with $\mathrm{LBP}^{11)}$.

Besides psychological factors, socio-demographic, lifestyle and work-related factors have been well studied as the potential predictors that contributed to the $\mathrm{LBP}^{2,3)}$. However, only limited studies have been conducted considering all these factors among teachers' population. Therefore, we aim to assess the course of LBP and determine the predictors of LBP among school teachers.

\section{Subjects and Methods}

A longitudinal study was conducted with a 1 year follow-up. The measurements were conducted on three separated periods consisting of baseline, first and second follow-up. The baseline study was conducted between May and October 2015 using self-administered questionnaires. First follow-up measurement was carried out from November 2015 to April 2016 (6-month follow-up) using telephone interviews. Meanwhile, the second followup was conducted from May to October 2016 (12-month follow-up) using a self-administered questionnaire.

The study was conducted in Selangor, the most developed and progressive state in Malaysia. Fifty percent of all public secondary schools in all the ten districts from the Selangor were randomly selected and invited to participate. Among the selected schools, there were
83 urban schools and 33 rural schools. All teachers from the selected schools were invited to participate. Their participation was entirely voluntary. Teachers who were pregnant, would be retiring within one-year, and medically diagnosed with MSD were excluded. Ethical approval was obtained from the Medical Ethics Committee of the University Malaya Medical Centre (UMMC) (Reference Number: MEC 950.1). Written informed consent was obtained from all participants prior to data collection.

\section{Sample size estimation}

The sample size of the study population was calculated using OpenEpi version 3.01 software for cohort study. Several information was needed for sample size calculation which were two sided $95 \%$ confidence interval, power of $80 \%$, a ratio of unexposed to exposed in a sample, percent of unexposed with the outcome and risk estimate (prevalence rate ratio (PRR)). Based on the study by Sadeghian et al., three factors namely history of LBP, work-related and psychological factors were selected for sample size calculation $^{12)}$. Finally, the largest calculated sample size was 536.

\section{Data collection instruments}

A self-administered questionnaire was used to obtain responses from the participants at baseline and 12-month follow-up. Within two weeks, a text was sent to them as a reminder to complete the questionnaires. Participants were required to put the completed questionnaires in the sealed envelopes before placing at the school's office or in their pigeon-hole units. The questionnaire was collected by the author from the individual schools.

The questionnaire consists of socio-demographic information such as age, gender and ethnicity. The International Physical Activity Questionnaire (IPAQ) was used to assess the levels of physical activity. The total daily activities were computed based on IPAQ scoring guidelines and was categorised as low ( $<600 \mathrm{MET}-\mathrm{min} / \mathrm{wk})$, moderate (600-1,499 MET-min/wk) and vigorous ( $\geq 1,500$ MET$\mathrm{min} / \mathrm{wk}$ ) activity ${ }^{13)}$. Body mass index (BMI) was calculated based on the self-reported measure of weight and height. BMI was calculated with the formula of weight $(\mathrm{kg}) /$ height $^{2}$ (metre $)^{2}$ and was classified as underweight (BMI $<18.5 \mathrm{~kg} / \mathrm{m}^{2}$ ), normal weight (BMI $18.5-24.9 \mathrm{~kg} /$ $\mathrm{m}^{2}$ ), overweight (BMI 25.0-29.9 $\mathrm{kg} / \mathrm{m}^{2}$ ) and obese (BMI $\geq 30.0 \mathrm{~kg} / \mathrm{m}^{2}$ ). Self-reported weight and height was used as the previous study has found that self-reported weight and height were consistent with direct measurements ${ }^{14)}$.

Work physical factors were assessed based on the standardised Dutch Musculoskeletal Questionnaire and 
International Study of Physical, Cultural and Psychosocial Influences on Musculoskeletal Symptoms and Associated Disability (CUPID study) Questionnaire ${ }^{15)}$. The physical work-related factors included were prolonged sitting, prolonged standing, lifting weights $\geq 25 \mathrm{~kg}$ by hand and climbing $>30$ flights of stairs a day.

Work-related psychosocial factors were measured using the Job Content Questionnaire (JCQ). JCQ is a 22-item questionnaire with responses for each item ranging from 1 (strongly disagree) to 4 (strongly agree). Taking into account of the demand-control-support model as proposed by Karasek and Theorell, it includes categorical data on demand-control (strain job and no-strain job) as well as categorical data on social support (high social support and low social support) ${ }^{16)}$. The demand-control-support was classified into four groups: a) no-strain and high social support; b) no-strain and low social support; c) strain and high social support; and d) strain and low social support.

Four instruments were used to assess psychological factors and symptoms. Symptoms of depression, and anxiety were assessed using the 21-item Depression Anxiety Stress Scale (DASS-21). The scale for each item ranged from 0 "did not apply to me at all" to 3 "applied to me very much or most of the time". The total scores for each subscale ranged between 0 and 21 . The total scored for each subscale was multiplied with two prior to categorising the symptoms according to their severity. A total scores of 0-7 for the anxiety subscales was categorised as normal, 8-14 as mild to moderate, and $15-42$ as severe to extremely severe. Meanwhile, total scores of 0-9 for the depression subscale were categorized as normal, $10-20$ as mild to moderate, and $21-42$ as severe to extremely severe ${ }^{17)}$. The scores for the stress subscale was not used in this study.

The pain catastrophising scale (PCS) was used to determine their level of thoughts or feelings when experiencing pain. This scale consists of 13 items where each item ranged from 0 (not at all) to 4 (all the time). The total score was computed by summing all the responses, ranging from 0 to 52 . The total score of pain catastrophising were categorized into three groups which were normal $(0-3)$, moderate (4-19) and high (20-52).

The health belief of LBP was assessed using the modified Fear-Avoidance Belief Questionnaire (mFABQ). The original FABQ comprises of two subscales, which are physical activity subscale (FABQ-PA) and work subscale (FABQ-W). FABQ-PA and FABQ-W contain five and eleven items, respectively. The scale for each item ranged between 0 (strongly disagree) to 6 (strongly agree). In this study, the FABQ was modified (mFABQ) to ensure that all questions can be answered by the participants without LBP. Therefore, we adopted four items of FABQ-PA from the past study conducted by Buer and Linton ${ }^{18)}$ and seven items of FABQ-W from a study by Myhre et al ${ }^{19)}$. A pilot study has been conducted to evaluate the construct validity of the instrument in our population. Confirmatory factor analysis was conducted to evaluate its factor loading. The analysis suggested dropping an item from the mFABQPA and two items from mFABQ-W. For physical activity, the values of factor loading ranged between 0.83 and 0.95 , whereas for work, the values ranged between 0.72 and 0.94 . The Cronbach's alpha for the total score of modified FAB on physical activity and work subscales were 0.92 and 0.93 respectively. The scoring was similar with the original. The total scores of the three items (mFABQ-PA) and five items (mFABQ-W) were between 0-18 and 0-30 respectively. Total score of mFABQ-PA was then dichotomized into low health belief (0-8) and high health belief (9-18). Meanwhile, total score mFABQ-W was then dichotomized into low health belief (0-14) and high health belief (15-30).

The somatising tendency was assessed using the Brief Symptom Inventory (BSI) Questionnaire with seven items. These items asked about the experience of nausea, faintness, dizziness, weakness, numbness in the body, chest pain and breathing difficulty over the past week. Those who reported two to seven symptoms with ratings of at least moderately distressing were defined as having somatisation tendency ${ }^{15}$.

The questions on LBP were assessed using the Nordic Musculoskeletal Questionnaire (NMQ) accompanied by anatomical diagrams depicting the specified sites. LBP was defined as self-reported pain in the region of the lower back that lasted for at least one day with a binary response (yes/no). Self-reported LBP was measured at baseline, 6and 12-month follow-ups. At baseline, the participants were asked if they ever had LBP for more than one day in the past 12 months. For 6- and 12-month follow-ups, the participants were asked if they ever had LBP for more than one day in the past 6 months.

\section{Definition of outcome}

The main outcome of this study was the occurrence of LBP at 12-month follow-up. This was created based on its definition of which participants were considered to have LBP when they reported LBP at 6-month and/or 12-month follow-up. Participants considered to have LBP if they had LBP either at both follow-up (6 and 12-month) or they had LBP at only one follow-up (6 or 12-month). 
Analysis

Statistical analyses were performed using Stata version 13.0 software. The analysis only included participants who responded to all three follow ups. The categorical data were described by presenting frequency and percentage. Continuous data were presented in terms of mean and standard deviation. $\chi^{2}$ test was used to determine the difference between the proportions of predictors and outcome. Logistic regression was utilised to establish the predictors of LBP. In the multivariate analysis, three models were presented. In multivariate logistic regression (Model 1), we included confounders namely socio-demographic, lifestyle and work-related factors. Model 2 comprised of Model $1+$ exposures such as pain catastrophizing, fear avoidance belief, symptoms of depression and anxiety and somatising tendency. Model 3 comprised of Model $2+$ LBP at baseline. Associations were summarised in terms of odds ratio (OR) with $95 \%$ confidence interval (CI). Statistical significance was set at the 5\% level.

\section{Results}

Out of the 116 selected secondary schools, 70 schools $(60.3 \%)$ agreed to participate in this study. Out of 70 schools, there were 22 rural and 48 urban schools. One thousand two hundred and eighty eligible teachers were invited for the study, of which 1037 (81.0\%) responded. At 6-month follow-up, $890(85.8 \%)$ responded to the phone interviews, and $701(67.6 \%)$ returned the questionnaire at 12-month follow-up.

\section{Distribution of the course of LBP at baseline and 12-month follow-up}

The prevalence of LBP at baseline and 12-month follow-up was $48.1 \%$ (95\%CI: $45.6 \%, 51.7 \%$ ) and $44.4 \%$ (95\%CI: 40.6\%, 48.0\%), respectively (Table 1). Among those with LBP at baseline, 238 (70.6\%) of them had LBP at 12-month follow-up. Meanwhile, among 364 participants who were initially free of LBP at baseline, 73 (20.1\%) of them experienced LBP at 12-month follow-up.

Distribution characteristics of participants by sociodemographic, lifestyle, work-related, psychological factors and LBP at baseline

The mean age of participants was $40.2 \mathrm{yr}$ (standard deviation (SD): 9.1). Majority of them were Malay (82.4\%) and females (85.7\%). Most of the participants had normal BMI (43.4\%) followed by overweight (34.7\%), obese $(18.1 \%)$ and underweight (3.8\%). About half of them
$(59.3 \%)$ reported low level of physical activity $(<600$ MET-min/wk) (Table 1).

Most of the participants lifted weights $\geq 25 \mathrm{~kg}$ by hand $(92.5 \%)$, climbed up or down $>30$ flights of stairs a day (98.4\%), had prolonged sitting (87.4\%) and prolonged standing (97.7\%). Most participants had high social support and low job strain (low demand and high control) with $69.7 \%$ and $81.1 \%$, respectively. Meanwhile, most participants had a moderate level of pain catastrophising (48.4\%), high fear avoidance belief about physical activity $(68.2 \%)$ and work (59.4\%), normal symptoms of anxiety (47.1\%) and depression (69.7\%) and low level of somatising tendency $(65.6 \%)$.

The proportion of LBP at 12-month follow-up was higher among those who had been lifting weights $\geq 25 \mathrm{~kg}$ by hand $(p<0.001)$. There were also higher proportions of LBP at 12-month follow-up among those who had pain catastrophising, fear avoidance about physical activity and work, symptoms of depression and anxiety, and somatising tendency (all $p<0.001$ ). Meanwhile, the proportion of LBP at 12-month follow up was higher among those who had LBP at baseline $(p<0.001)$.

Association between baseline characteristics and LBP at 12-month follow-up

None of the socio-demographic factors (age, gender, and ethnicity) was significantly associated with LBP at 12-month follow-up (Table 2). BMI and physical activity level were also not significantly associated with LBP at 12-month follow-up.

For work-related physical factor, only lifting weights $\geq 25 \mathrm{~kg}$ by hand was significantly associated with LBP at 12-month follow-up. Prolonged standing, prolonged sitting and climbing up or down $>30$ flights of stairs a day were not significantly associated with LBP. Meanwhile, workrelated psychosocial factors namely low social support and high job strain were also not significantly associated with LBP at 12-month follow-up.

LBP at baseline and psychological factors including pain catastrophising, fear-avoidance beliefs about physical activity and work, symptoms of anxiety and depression and somatising tendency, were significantly associated with LBP at 12-month follow-up.

Multivariate analysis between baseline characteristics and LBP at 12-month follow-up

Table 3 shows the multivariate analysis of all the predictors affecting LBP at 12-month follow up. Lifting weights $\geq 25 \mathrm{~kg}$ by hand was significantly associated with 
Table 1. Characteristics of participants by socio-demographic, lifestyle, work-related, psychological factors and LBP at baseline with LBP at 12-month follow-up $(\mathrm{N}=701)$

\begin{tabular}{|c|c|c|c|c|}
\hline \multirow{2}{*}{ Variables } & \multirow{2}{*}{ Total, N (\%) } & \multicolumn{2}{|c|}{ LBP at 12-month follow-up, n (\%) } & \multirow{2}{*}{$p$-value } \\
\hline & & No & Yes & \\
\hline \multicolumn{5}{|l|}{ Socio-demographic factor } \\
\hline \multicolumn{5}{|l|}{ Age (yr) [Mean (SD): $40.23(9.07)](\mathrm{n}=679)$} \\
\hline$<30$ & $84(12.4)$ & $51(60.7)$ & $33(39.3)$ & 0.506 \\
\hline $30-39$ & $237(34.9)$ & $127(53.6)$ & $110(46.4)$ & \\
\hline $40-49$ & $236(34.8)$ & $128(54.2)$ & $108(45.8)$ & \\
\hline$\geq 50$ & $122(17.9)$ & $73(59.8)$ & $49(40.2)$ & \\
\hline \multicolumn{5}{|l|}{ Gender } \\
\hline Female & $601(85.7)$ & $340(56.6)$ & $261(43.4)$ & 0.221 \\
\hline Male & $100(14.3)$ & $50(50.0)$ & $50(50.0)$ & \\
\hline \multicolumn{5}{|l|}{ Ethnicity } \\
\hline Malay & $578(82.4)$ & $318(55.0)$ & $260(45.0)$ & 0.756 \\
\hline Chinese & $54(7.7)$ & $31(57.4)$ & $23(42.6)$ & \\
\hline Indian & $69(9.9)$ & $41(59.4)$ & $28(40.6)$ & \\
\hline \multicolumn{5}{|l|}{ Body Mass Index $\left(\mathrm{kg} / \mathrm{m}^{2}\right)(\mathrm{n}=662)$} \\
\hline Underweight $(<18.5)$ & $25(3.8)$ & $15(60.0)$ & $10(40.0)$ & 0.557 \\
\hline Normal (18.5-24.9) & $287(43.4)$ & $168(58.5)$ & $119(41.5)$ & \\
\hline Overweight (25.0-29.9) & $230(34.7)$ & $125(54.3)$ & $105(45.7)$ & \\
\hline Obesity $(\geq 30.0)$ & $120(18.1)$ & $62(51.7)$ & $58(48.3)$ & \\
\hline \multicolumn{5}{|c|}{ Level of physical activity (MET-min/wk) $(\mathrm{n}=376)$} \\
\hline Low $(<600)$ & $223(59.3)$ & $124(55.6)$ & $99(44.4)$ & 0.942 \\
\hline Moderate $(600-1,499)$ & $82(21.8)$ & $46(56.1)$ & $36(43.9)$ & \\
\hline High $(>1,500)$ & $71(18.9)$ & $38(53.5)$ & $33(46.5)$ & \\
\hline \multicolumn{5}{|l|}{ Work-related physical factors } \\
\hline \multicolumn{5}{|l|}{ Lifting weights $\geq 25 \mathrm{~kg}$ by hand $(\mathrm{n}=690)$} \\
\hline No & $52(7.5)$ & $42(80.8)$ & $10(19.2)$ & $<0.001 *$ \\
\hline Yes & $638(92.5)$ & $342(53.6)$ & $296(46.4)$ & \\
\hline \multicolumn{5}{|c|}{ Climbing up or down $>30$ flights of stairs a day $(n=688)$} \\
\hline No & $11(1.6)$ & $6(54.5)$ & $5(45.5)$ & 0.948 \\
\hline Yes & $677(98.4)$ & $376(55.5)$ & $307(44.5)$ & \\
\hline \multicolumn{5}{|l|}{ Prolonged sitting $(\mathrm{n}=691)$} \\
\hline No & $87(12.6)$ & $44(50.6)$ & $43(49.4)$ & 0.316 \\
\hline Yes & $604(87.4)$ & $340(56.3)$ & $264(43.7)$ & \\
\hline \multicolumn{5}{|l|}{ Prolonged standing $(n=692)$} \\
\hline No & $16(2.3)$ & $12(75.0)$ & $4(25.0)$ & 0.115 \\
\hline Yes & $676(97.7)$ & $373(55.2)$ & $303(44.8)$ & \\
\hline \multicolumn{5}{|l|}{ Work-related psychosocial factors } \\
\hline \multicolumn{5}{|l|}{ Social support $(\mathrm{n}=673)$} \\
\hline Low & $204(30.3)$ & $107(52.4)$ & 97 (47.6) & 0.306 \\
\hline High & $469(69.7)$ & $266(56.7)$ & $203(43.3)$ & \\
\hline \multicolumn{5}{|l|}{ Demand control (job strain) $(n=657)$} \\
\hline Low & $533(81.1)$ & $291(54.6)$ & $242(45.4)$ & 0.305 \\
\hline High & $124(18.9)$ & $74(59.68)$ & $50(40.32)$ & \\
\hline \multicolumn{5}{|l|}{ Demand control-support $(\mathrm{n}=641)$} \\
\hline Low job strain and high social support & $385(60.1)$ & $211(54.8)$ & $174(45.2)$ & 0.322 \\
\hline Low job strain and low social support & $134(20.9)$ & $70(52.2)$ & $64(47.8)$ & \\
\hline High job strain and high social support & $62(9.6)$ & $41(66.1)$ & $21(33.9)$ & \\
\hline High job strain and low social support & $60(9.4)$ & $33(55.0)$ & $27(45.0)$ & \\
\hline
\end{tabular}


Table 1. Continued

\begin{tabular}{|c|c|c|c|c|}
\hline \multirow{2}{*}{ Variables } & \multirow{2}{*}{ Total, N (\%) } & \multicolumn{2}{|c|}{ LBP at 12 -month follow-up, $\mathrm{n}(\%)$} & \multirow{2}{*}{$p$-value } \\
\hline & & No & Yes & \\
\hline \multicolumn{5}{|l|}{ Psychological factors } \\
\hline \multicolumn{5}{|l|}{ Pain catastrophizing $(\mathrm{n}=671)$} \\
\hline Normal & $177(26.4)$ & $118(66.7)$ & $59(33.3)$ & $<0.001^{*}$ \\
\hline Moderate & $325(48.4)$ & $179(55.1)$ & $146(44.9)$ & \\
\hline High & $169(25.2)$ & $79(46.8)$ & $90(53.2)$ & \\
\hline \multicolumn{5}{|c|}{ Fear avoidance belief (physical activity) $(\mathrm{n}=648)$} \\
\hline Low & $206(31.8)$ & $131(63.6)$ & $75(36.4)$ & $<0.001^{*}$ \\
\hline High & $442(68.2)$ & $226(51.1)$ & $216(48.9)$ & \\
\hline \multicolumn{5}{|c|}{ Fear avoidance belief (work) $(\mathrm{n}=562)$} \\
\hline Low & $228(40.6)$ & $147(64.5)$ & $81(35.5)$ & $<0.001^{*}$ \\
\hline High & $334(59.4)$ & $168(50.3)$ & $166(49.7)$ & \\
\hline \multicolumn{5}{|l|}{ Anxiety symptom $(\mathrm{n}=684)$} \\
\hline Normal & $322(47.1)$ & $201(62.4)$ & $121(37.6)$ & $<0.001 *$ \\
\hline Mild to moderate & $220(32.2)$ & $128(58.2)$ & $92(41.8)$ & \\
\hline Severe to extremely severe & $142(20.7)$ & $52(36.6)$ & $90(63.4)$ & \\
\hline \multicolumn{5}{|l|}{ Depression symptom $(\mathrm{n}=677)$} \\
\hline Normal & $472(69.7)$ & $284(60.2)$ & $188(39.8)$ & $<0.001 *$ \\
\hline Mild to moderate & $186(27.5)$ & $91(48.9)$ & $95(51.1)$ & \\
\hline Severe to extremely severe & $19(2.8)$ & $7(36.8)$ & $12(63.2)$ & \\
\hline \multicolumn{5}{|l|}{ Somatising tendency $(n=692)$} \\
\hline Low & $454(65.6)$ & $283(62.3)$ & $171(37.7)$ & $<0.001^{*}$ \\
\hline High & $238(34.4)$ & $104(43.7)$ & $134(56.3)$ & \\
\hline \multicolumn{5}{|l|}{ LBP at baseline } \\
\hline No & $364(51.9)$ & $291(79.9)$ & $73(20.1)$ & \\
\hline Yes & $337(48.1)$ & $99(29.4)$ & $238(70.6)$ & $<0.001^{*}$ \\
\hline
\end{tabular}

${ }^{*} p$-value $<0.05$-significant association. LBP: low back pain.

LBP in Models 1 and 2. Among other psychological factors, none of them were significantly associated with LBP except anxiety (Model 2). Meanwhile, there was only LBP at baseline significantly associated with LBP at 12-month follow up (Model 3).

\section{Discussion}

The prevalence of LBP among the participants at baseline and 12-month follow-up was $48.0 \%$ and $44.3 \%$, respectively. This indicated that the occurrence of LBP was considerably prevalent among these secondary school teachers. The prevalence at baseline seemed comparable with other local cross-sectional studies ranging from $40.4 \%$ to $56.7 \%{ }^{20-22)}$. Meanwhile, the prevalence of LBP at 12-month follow-up was comparable to another longitudinal study reported $45.7 \%$ among other occupational cohort $^{6}$. Participants with LBP reported at baseline were more likely to recur $(70.63 \%)$, which suggested that LBP was often chronic or recurrent.
Previous studies found that female teachers were more likely to develop $\mathrm{LBP}^{2,23)}$. This may be due to females were more likely to have a lower pain threshold compared to males ${ }^{24)}$. Nevertheless, we did not find any significant association between gender and LBP, similarly reported by another local study ${ }^{21)}$. Exposure to work-related physical and psychological factors were more likely to predispose to LBP regardless of gender. Our findings showed no significant association between age and LBP and a similar result was reported by Erick and Smith ${ }^{2}$. Another study found that age was significantly associated with specific LBP such as osteoporosis ${ }^{25}$. Osteoporosis was common among the elderly due to age-related bone loss. For that reason, age may be a contributing factor for specific LBP instead of non-specific LBP. Another reason could be due the presence of healthy worker effect. The healthy worker effect is the source of selection bias in which the presence of healthy workers in all age groups might wholly or partially masked the true effect of association between age and LBP. 
Table 2. Association between baseline characteristics and low back pain (LBP) at 12-month follow-up

\begin{tabular}{|c|c|c|c|}
\hline Variables & $\begin{array}{l}\text { LBP at } 12 \text {-month follow-up, } \\
\text { OR }(95 \% \mathrm{CI})\end{array}$ & Variables & $\begin{array}{l}\text { LBP at } 12 \text {-month follow-up, } \\
\text { OR }(95 \% \mathrm{CI})\end{array}$ \\
\hline Sociodemographic factors & & Work-related psychosocial factors & \\
\hline Age group (yr) & & Demand control-support & \\
\hline$<30$ & 1.0 & Low job strain and high social support & 1.0 \\
\hline $30-39$ & $1.33(0.80,2.22)$ & Low job strain and low social support & $1.18(0.74,1.64)$ \\
\hline $40-49$ & $1.30(0.78,2.16)$ & High job strain and high social support & $0.62(0.35,1.09)$ \\
\hline$\geq 50$ & $1.03(0.58,1.83)$ & High job strain and low social support & $0.99(0.57,1.71)$ \\
\hline Gender (Female) & & Individual psychological factors & \\
\hline Male & 1.0 & Pain catastrophising & \\
\hline Female & $0.76(0.50,1.17)$ & Normal & 1.0 \\
\hline Races & & Moderate & $1.63(1.14,2.38)^{*}$ \\
\hline Malay & 1.0 & High & $2.27(1.47,3.51)^{*}$ \\
\hline Chinese & $0.90(0.51,1.59)$ & Fear avoidance belief (physical activity) & \\
\hline Indian & $0.83(0.50,1.38)$ & Low & 1.0 \\
\hline Body Mass Index $\left(\mathrm{kg} / \mathrm{m}^{2}\right)$ & & High & $1.66(1.18,2.34)^{*}$ \\
\hline Underweight $(<18.5)$ & $0.94(0.40,2.16)$ & Fear avoidance belief (work) & \\
\hline Normal (18.5-24.9) & 1.0 & Low & 1.0 \\
\hline Overweight (25.0-29.9) & $1.18(0.83,1.68)$ & High & $1.79(1.26,2.53)^{*}$ \\
\hline Obesity $(\geq 30.0)$ & $1.32(0.86,2.02)$ & Anxiety symptom & \\
\hline Level of physical activity (MET-min/wk) & & Normal & 1.0 \\
\hline Low $(<600)$ & $0.91(0.53,1.57)$ & Mild to moderate & $1.19(0.84,1.69)$ \\
\hline Moderate $(600-1,499)$ & $0.90(0.47,1.70)$ & Severe to extremely severe & $2.87(1.90,4.32)^{*}$ \\
\hline High $(>1,500)$ & 1.0 & Depression symptom & \\
\hline Work-related physical factors & & Normal & 1.0 \\
\hline Lifting weights $\geq 25 \mathrm{~kg}$ by hand & & Mild to moderate & $1.57(1.12,2.21)^{*}$ \\
\hline No & 1.0 & Severe to extremely severe & $2.58(1.01,6.69)^{*}$ \\
\hline Yes & $3.63(1.79,7.37)^{*}$ & Somatising tendency & \\
\hline Climbing up or down $>30$ flights of stairs & a day & Low & 1.0 \\
\hline No & 1.0 & High & $2.13(1.55,2.93)^{*}$ \\
\hline Yes & $0.96(0.29,3.17)$ & LBP at baseline & \\
\hline Prolonged sitting & & No & 1.0 \\
\hline No & 1.0 & Yes & $9.58(6.76,13.56)^{*}$ \\
\hline Yes & $0.79(0.50,1.24)$ & & \\
\hline \multicolumn{4}{|l|}{ Prolonged standing } \\
\hline No & 1.0 & & \\
\hline Yes & $2.43(0.77,7.63)$ & & \\
\hline
\end{tabular}

Results of multivariate analysis (Model 2) showed a significant association between lifting heavy weight and LBP at 12-month follow-up. Studies on the association between lifting heavy weight and LBP among teachers yielded inconsistent results. Some studies showed that lifting heavy weight was not significantly associated with LBP among school teachers ${ }^{2,3}$. On the other hand, a significant association was found between lifting heavy weights and LBP among primary, secondary and higher institutions (college and university) teachers in Ethiopia ${ }^{26}$, and male secondary school teachers in Saudi Arabia ${ }^{27)}$. Lifting is a dynamic and highly variable type of physical exposure that can be quantified in duration, frequency and intensity (the weight of the load lifted) that contributes differently to mechanical low back load ${ }^{28)}$. In the present study, it was found that the high intensity of weight lifting might cause sudden injury to the muscles and ligaments supporting the back. It might also mediate through psychological influences on pain perception which might lead the individuals to report LBP. 
Table 3. Multivariate models between predictors and low back pain (LBP) at 12-month follow up

\begin{tabular}{|c|c|c|c|}
\hline \multirow{2}{*}{ Variables } & \multicolumn{3}{|c|}{ LBP at 12 -month follow-up, OR $(95 \% \mathrm{CI})$} \\
\hline & Model 1 & Model 2 & Model 3 \\
\hline \multicolumn{4}{|l|}{ Sociodemographic factors } \\
\hline \multicolumn{4}{|l|}{ Age group (yr) } \\
\hline$<30$ & 1.0 & 1.0 & 1.0 \\
\hline $30-39$ & $1.22(0.71,1.72)$ & $1.26(0.62,2.54)$ & $1.76(0.62,4.97)$ \\
\hline $40-49$ & $0.73(0.40,1.32)$ & $1.20(0.56,2.54)$ & $1.02(0.33,3.15)$ \\
\hline$\geq 50$ & $1.00(0.56,1.78)$ & $0.74(0.29,1.85)$ & $0.42(0.09,2.00)$ \\
\hline \multicolumn{4}{|l|}{ Gender } \\
\hline Male & 1.0 & 1.0 & 1.0 \\
\hline Female & $0.69(0.43,1.11)$ & $0.81(0.44,1.49)$ & $0.64(0.26,1.55)$ \\
\hline \multicolumn{4}{|l|}{ Races } \\
\hline Malay & 1.0 & 1.0 & 1.0 \\
\hline Chinese & $0.89(0.45,1.75)$ & $0.96(0.39,2.33)$ & $0.26(0.04,1.52)$ \\
\hline Indian & $1.00(0.55,1.79)$ & $1.69(0.79,3.62)$ & $3.22(0.94,11.03)$ \\
\hline \multicolumn{4}{|l|}{ Body Mass Index $\left(\mathrm{kg} / \mathrm{m}^{2}\right)$} \\
\hline Underweight $(<18.5)$ & $1.19(0.49,2.91)$ & $0.76(0.20,2.82)$ & $1.95(0.34,11.17)$ \\
\hline Normal (18.5-24.9) & 1.0 & 1.0 & 1.0 \\
\hline Overweight (25.0-29.9) & $1.30(0.87,1.92)$ & $1.21(0.73,1.98)$ & $0.97(0.45,2.08)$ \\
\hline Obesity $(\geq 30.0)$ & $1.31(0.80,2.13)$ & $0.95(0.52,1.73)$ & $0.68(0.27,1.70)$ \\
\hline \multicolumn{4}{|l|}{ Level of physical activity (MET-min/wk) } \\
\hline Low $(<600)$ & $0.93(0.50,1.74)$ & $0.94(0.42,2.06)$ & $0.74(0.28,1.94)$ \\
\hline Moderate $(600-1,499)$ & $1.06(0.51,2.18)$ & $0.74(0.29,1.84)$ & $0.59(0.19,1.77)$ \\
\hline $\operatorname{High}(>1,500)$ & 1.0 & 1.0 & 1.0 \\
\hline \multicolumn{4}{|l|}{ Lifting weights $\geq 25 \mathrm{~kg}$ by hand } \\
\hline No & 1.0 & 1.0 & 1.0 \\
\hline Yes & $3.03(1.36,6.77)^{*}$ & $4.16(1.40,12.30)^{*}$ & $3.22(0.95,10.92)$ \\
\hline \multicolumn{4}{|c|}{ Climbing up or down $>30$ flights of stairs a day } \\
\hline No & 1.0 & 1.0 & 1.0 \\
\hline Yes & $0.27(0.04,1.73)$ & $0.23(0.02,2.42)$ & $0.28(0.01,5.38)$ \\
\hline \multicolumn{4}{|l|}{ Prolonged sitting } \\
\hline No & 1.0 & 1.0 & 1.0 \\
\hline Yes & $0.60(0.35,1.03)$ & $0.75(0.37,1.48)$ & $0.84(0.39,1.83)$ \\
\hline \multicolumn{4}{|l|}{ Prolonged standing } \\
\hline No & 1.0 & 1.0 & 1.0 \\
\hline Yes & $4.16(0.92,18.67)$ & $6.14(0.94,40.13)$ & $3.12(0.37,25.98)$ \\
\hline \multicolumn{4}{|l|}{ Demand control-support } \\
\hline Low job strain \& high social support & 1.0 & 1.0 & 1.0 \\
\hline Low job strain \& low social support & $1.12(0.73,1.72)$ & $0.73(0.42,1.29)$ & $0.62(0.33,1.18)$ \\
\hline High job strain \& high social support & $0.73(0.40,1.32)$ & $1.19(0.56,2.52)$ & $1.36(0.59,3.16)$ \\
\hline High job strain \& low social support & $1.00(0.56,1.78)$ & $0.84(0.41,1.72)$ & $0.80(0.36,1.78)$ \\
\hline \multicolumn{4}{|l|}{ Individual psychological factors } \\
\hline \multicolumn{4}{|l|}{ Pain catastrophising } \\
\hline Normal & - & 1.0 & 1.0 \\
\hline Moderate & - & $0.88(0.51,1.51)$ & $0.70(0.37,1.32)$ \\
\hline High & - & $0.92(0.47,1.79)$ & $0.71(0.32,1.52)$ \\
\hline \multicolumn{4}{|l|}{ Fear avoidance belief (physical activity) } \\
\hline Low & - & 1.0 & 1.0 \\
\hline High & - & $1.01(0.58,1.74)$ & $0.68(0.36,1.27)$ \\
\hline
\end{tabular}


Table 3. Continued

\begin{tabular}{|c|c|c|c|}
\hline \multirow{2}{*}{ Variables } & \multicolumn{3}{|c|}{ LBP at 12 -month follow-up, OR $(95 \% \mathrm{CI})$} \\
\hline & Model 1 & Model 2 & Model 3 \\
\hline \multicolumn{4}{|c|}{ High fear avoidance belief (work) } \\
\hline Low & - & 1.0 & 1.0 \\
\hline High & - & $1.55(0.92,2.64)$ & $1.36(0.75,2.48)$ \\
\hline \multicolumn{4}{|l|}{ High somatising tendency } \\
\hline Low & - & 1.0 & 1.0 \\
\hline High & - & $1.11(0.65,1.89)$ & $0.91(0.49,1.66)$ \\
\hline \multicolumn{4}{|l|}{ Anxiety symptom } \\
\hline Normal & - & 1.0 & 1.0 \\
\hline Mild to moderate & - & $1.94(1.12,3.36)^{*}$ & $1.73(0.93,3.23)$ \\
\hline Severe to extremely severe & - & $2.51(1.19,5.30)^{*}$ & $2.24(0.95,5.27)$ \\
\hline \multicolumn{4}{|l|}{ Depression symptom } \\
\hline Normal & - & 1.0 & 1.0 \\
\hline Mild to moderate & - & $0.84(0.46,1.53)$ & $1.06(0.54,2.11)$ \\
\hline Severe to extremely severe & - & $3.67(0.35,37.80)$ & $3.25(0.28,37.30)$ \\
\hline \multicolumn{4}{|l|}{ LBP at baseline } \\
\hline No & - & - & 1.0 \\
\hline Yes & - & - & $10.43(6.19,17.58)^{*}$ \\
\hline \multicolumn{4}{|l|}{$* p$-value $<0.05$} \\
\hline \multicolumn{4}{|c|}{ OR: odds ratio; CI: confidence interval. } \\
\hline \multicolumn{4}{|c|}{$\begin{array}{l}\text { Model 1: analysis including confounders (sociodemographic and lifestyle factors, body mass index and work-related factors (physical ar } \\
\text { psychosocial)). }\end{array}$} \\
\hline \multicolumn{4}{|c|}{$\begin{array}{l}\text { Model 2: Model } 1+\text { psychological factors (pain catastrophizing, fear-avoidance belief, somatising tendency, depression and anxiety symp } \\
\text { toms). }\end{array}$} \\
\hline
\end{tabular}

Despite the influence of work-related physical factor on LBP, previous studies demonstrated the stronger influence of psychological factors on LBP. While past studies found a significant association between fear-avoidance belief and $\mathrm{LBP}^{18,29)}$, our multivariate results showed vice versa. The reason for the loss of statistical significance of fear-avoidance belief in the multivariate models remains unclear. We postulated these occured due to the presence of confounders that obscured real effects between fearavoidance belief and LBP. Future studies of fear-avoidance belief and LBP should be conducted in detail and included other psychological factors as well to seek confirmation of its association.

Meanwhile, we found anxiety was the only psychological factor significantly associated with LBP at 12-month follow-up (Model 2). The odds of having LBP was 51\% higher for those who had severe anxiety, similarly reported in another local study ${ }^{21}$. Challenges in the education system and multiple pressures from schools, students, parents and community may cause anxiety among teachers. The non-significant association between LBP at 12-month follow-up with other psychological factors (pain catastro- phizing, fear-avoidance, depression and somatization) indicated that anxiety might play a stronger role in the occurrence of LBP at 12-month follow-up compared to other psychological factors. Further studies should be conducted to explore this in detail.

It was undeniable teachers have been burdened with high job demands and workloads such as too many students, too much paperwork (non-teaching duties), too little time for lesson preparation and too many mindless interruptions and deadlines. Even so, we could not find significant association between demand-control support with LBP in the multivariate model (Model 2). This suggested that the occurrence of LBP in our study population was more likely to be related to individual factors (anxiety) rather than the presence of psychosocial work conditions. On the other hand, previous cross-sectional studies conducted among teachers found significant association between work-related psychosocial factors such as low job satisfaction and high psychological job demand with LBP among teachers ${ }^{2}, 30$ ). The difference in study design used might explained the difference in findings.

In Model 3, anxiety had loss statistical significance with 
LBP at 12-month follow-up, when LBP at baseline was added in the model. Meanwhile, a significant association was found between LBP at baseline and LBP at 12-month follow-up. It was not surprising since both of the variables shared the similar characteristics and nature. This is in concordance with other studies that reported that previous LBP predicted future LBP ${ }^{6,7,12)}$. Although LBP at baseline represented the strongest factor among all the factors studied, the importance of anxiety and lifting heavy weight on LBP should also be emphasised.

\section{Limitations and strengths}

There are a few limitations that need to be addressed. The attrition rate of $14.1 \%$ at 6 -month and $32.4 \%$ at 12 -month follow up may be substantial, however the final sample that completed the study exceeded the calculated sample size. Furthermore, there was no significant difference in the baseline characteristics among those who completed and drop out from the study. It is noteworthy to mention that the response rate of schools was less than $70 \%$. However, there was no significant difference in school's location of those participated and not participated in the study. Thus, it increased the likelihood that this study results can be generalised to the schools in this state. Other factors such as years of work and the workload (hours of work per week) were not inquired in this study. Nevertheless, the previous study found years of working were significantly correlated with age ${ }^{31)}$. There were missing values in some of the variables which may affect the precision of the results. However, most of the variables reported an acceptable missing values which were less than $20 \%{ }^{32)}$. Moreover, this study did not include a detailed assessment of LBP in terms of severity and intensity. Future studies should incorporate these aspects.

On the other hand, the major strength of this study lies in its prospective design and evaluation of broad biopsychosocial factors for their contributions to LBP. Therefore, this is more likely to suggest a cause and effect relationship than a cross-sectional study. Furthermore, no similar studies were conducted among school teachers in Malaysia. In addition, the questionnaire used in this study was valid and reliable for both international and local use.

\section{Conclusion}

This study indicated that the occurrence of LBP was prevalent among secondary school teachers. LBP at 12-month follow up was strongly predicted by LBP at baseline. Lifting weights $\geq 25 \mathrm{~kg}$ by hand and anxiety symptoms were significantly associated with LBP at 12-month follow-up if LBP at baseline was not in the model. It is recommended to conduct annual health screening on LBP and anxiety among secondary school teachers followed by the implementation of ergonomic intervention in order to reduce the occurrence of LBP.

\section{Acknowledgments}

We would like to thank all the school administrators and teachers for their cooperation and participation in our study. The approval from the Ministry of Education, Malaysia for the conduct of the study is acknowledged. This work was supported by the Postgraduate Research Grant (PPP) Grant (UM.0001177/HRU.PR) from the University of Malaya, Kuala Lumpur.

\section{References}

1) Jamil H, Razak NA, Raju R, Mohamed AR (2007) Teacher professional development in Malaysia: issues and challenges. Africa-Asia University Dialogue for Educational Development Network, 85-102.

2) Erick PN, Smith DR (2014) Low back pain among school teachers in Botswana, prevalence and risk factors. BMC Musculoskelet Disord 15, 359. [Medline] [CrossRef]

3) Yue P, Liu F, Li L (2012) Neck/shoulder pain and low back pain among school teachers in China, prevalence and risk factors. BMC Public Health 12, 789. [Medline] [CrossRef]

4) Atlas A, Bondoc R, Garrovillas R, Lo R, Recinto J, Yu K (2007) Prevalence of low back pain among public high school teachers in the City of Manila. Philipp J Allied Health Sci 2, 34-40.

5) Ehrlich GE (2003) Low back pain. Bull World Health Organ 81, 671-6.

6) Sadeghian F, Hosseinzadeh S, Aliyari R (2014) Do psychological factors increase the risk for low back pain among nurses? A comparing according to cross-sectional and prospective analysis. Saf Health Work 5, 13-6. [Medline] [CrossRef]

7) Kolb E, Canjuga M, Bauer GF, Läubli T (2011) Course of back pain across 5 years: a retrospective cohort study in the general population of Switzerland. Spine 36, E268-73. [Medline] [CrossRef]

8) Vargas-Prada S, Coggon D (2015) Psychological and psychosocial determinants of musculoskeletal pain and associated disability. Best Pract Res Clin Rheumatol 29, 374-90. [Medline] [CrossRef]

9) Urquhart DM, Kelsall HL, Hoe VC, Cicuttini FM, Forbes AB, Sim MR (2013) Are psychosocial factors associated with low back pain and work absence for low back pain in an occupational cohort? Clin J Pain 29, 1015-20. [Medline] [CrossRef] 
10) Westman AE, Boersma K, Leppert J, Linton SJ (2011) Fear-avoidance beliefs, catastrophizing, and distress: a longitudinal subgroup analysis on patients with musculoskeletal pain. Clin J Pain 27, 567-77. [Medline] [CrossRef]

11) Henschke N, Ostelo RW, van Tulder MW, Vlaeyen JW, Morley S, Assendelft WJ, Main CJ (2010) Behavioural treatment for chronic low-back pain. Cochrane Database Syst Rev CD002014. [Medline]

12) Sadeghian F, Coggon D, Ntani G, Hosseinzadeh S (2015) Predictors of low back pain in a longitudinal study of Iranian nurses and office workers. Work 51, 239-44. [Medline] [CrossRef]

13) Committee Research of International Physical Activity Questionnaire I. Guidelines for Data Processing and Analysis of the International Physical Activity Questionnaire (IPAQ)-Short and Long Forms 2005. http:// www.ipaq.ki.se/scoring.htm. Accessed September 15, 2015.

14) Kee CC, Lim KH, Sumarni MG, Teh CH, Chan YY, Nuur Hafizah MI, Cheah YK, Tee EO, Ahmad Faudzi Y, Amal Nasir M (2017) Validity of self-reported weight and height: a cross-sectional study among Malaysian adolescents. BMC Med Res Methodol 17, 85. [Medline] [CrossRef]

15) Hoe VC, Kelsall HL, Urquhart DM, Sim MR (2012) Risk factors for musculoskeletal symptoms of the neck or shoulder alone or neck and shoulder among hospital nurses. Occup Environ Med 69, 198-204. [Medline] [CrossRef]

16) Karasek R, Theorell T (1992) Healthy work: stress, productivity, and the reconstruction of working life, Basic books, USA.

17) Lovibond SH, Lovibond PF (1995) Manual for the depression anxiety stress scales. Psychology Foundation of Australia, Sydney.

18) Buer N, Linton SJ (2002) Fear-avoidance beliefs and catastrophizing: occurrence and risk factor in back pain and ADL in the general population. Pain 99, 485-91. [Medline] [CrossRef]

19) Myhre K, Røe C, Marchand GH, Keller A, Bautz-Holter E, Leivseth G, Sandvik L, Lau B (2013) Fear-avoidance beliefs associated with perceived psychological and social factors at work among patients with neck and back pain: a cross-sectional multicentre study. BMC Musculoskelet Disord 14, 329. [Medline] [CrossRef]

20) Anuar NFM, Rasdi I, Saliluddin SM, Abidin EZ (2016) Work task and job satisfaction predicting low back pain among secondary school teachers in Putrajaya. Iran J Public Health 45, 85.

21) Zamri EN, Moy FM, Hoe VC (2017) Association of psychological distress and work psychosocial factors with self-reported musculoskeletal pain among secondary school teachers in Malaysia. PLoS One 12, e0172195. [Medline] [CrossRef]

22) Samad NIA, Abdullah H, Moin S, Tamrin SBM, Hashim Z (2010) Prevalence of low back pain and its risk factors among school teachers. Am J Appl Sci 7, 634-9. [CrossRef]

23) Cardoso JP, Ribeiro IdQB, Araújo TMd, Carvalho FM, Reis EJFBd (2009) Prevalence of musculoskeletal pain among teachers. Rev Bras Epidemiol 12, 604-14. [CrossRef]

24) Chong EY, Chan AH (2010) Subjective health complaints of teachers from primary and secondary schools in Hong Kong. Int J Occup Saf Ergon 16, 23-39. [Medline] [CrossRef]

25) El-Heis MA, Al-Kamil EA, Kheirallah KA, Al-Shatnawi TN, Gharaibia M, Al-Mnayyis A (2013) Factors associated with osteoporosis among a sample of Jordanian women referred for investigation for osteoporosis. East Mediterr Health J 19, 459-64. [Medline] [CrossRef]

26) Beyen TK, Mengestu MY, Zele YT (2013) Low back pain and associated factors among teachers in Gondar Town, North Gondar, Amhara Region, Ethiopia. Occup Med Health Aff 1, 1-8.

27) Badawood MA, Obaid H, Mohammed ME, Alrogi AJ (2017) Impact of low back pain on the work performance of male high school Saudi teachers in Taif City. J Health Inform Dev Ctries 11.

28) Coenen P, Gouttebarge V, van der Burght AS, van Dieën JH, Frings-Dresen MH, van der Beek AJ, Burdorf A (2014) The effect of lifting during work on low back pain: a health impact assessment based on a meta-analysis. Occup Environ Med 71, 871-7. [Medline] [CrossRef]

29) Oha K, Animägi L, Pääsuke M, Coggon D, Merisalu E (2014) Individual and work-related risk factors for musculoskeletal pain: a cross-sectional study among Estonian computer users. BMC Musculoskelet Disord 15, 181. [Medline] [CrossRef]

30) Yue P, Xu G, Li L, Wang S (2014) Prevalence of musculoskeletal symptoms in relation to psychosocial factors. Occup Med (Lond) 64, 211-6. [Medline] [CrossRef]

31) Chung J, Park J, Cho M, Park Y, Kim D, Yang D, Yang Y (2015) A study on the relationships between age, work experience, cognition, and work ability in older employees working in heavy industry. J Phys Ther Sci 27, 155-7. [Medline] [CrossRef]

32) Dong Y, Peng CY (2013) Principled missing data methods for researchers. Springerplus 2, 222. [Medline] [CrossRef] 